\title{
A Study on The Effect of Welding on Natural Frequencies of Thin Plate
}

\author{
Do-Yun Park ${ }^{a}$, Sung-Yong Bae and Jin-Ho Kim \\ Naval Architecture and Marine Systems Engineering, Pukyong National University, Pusan, \\ South Korea \\ a.ruinah31@naver.com
}

Keywords: Vibration Analysis, Natural Frequencies, Resonance, Welding, Fatigue Wreckage, Thin Plates

Abstract: Most constructions in civil engineering and aviation industry, are welded to arrange various structures. This trend is also found in shipbuilding and marine engineering, as the steel-plated structures of ship hull and offshore facilities are dominated by welding connections. Induced vibration from environment or people in the structures may cause severe casualties if proper estimations are not provided. In this case, vibration analysis is an essential element to prevent fatigue failure due to the resonance on both a moving structure such as automobile and ship, as well as general constructed building. While studies of dams and plates subjected to vibration behaviors have been conducted by many researchers, detail discussion related to interpretation of vibration characteristic on welded structures, especially plated structure such as ship is still limited. Thus, there is a need to conduct a further study concentrated on variations of natural frequencies generated by welding. This study aims to measure the natural frequencies of welded thin plates using experimental test, and analyze the qualitative tendency of the natural frequencies on the thin plate using numerical simulation. Results of the experiment is to be used as reference/benchmarking data in estimating quantitative basis of welding on the natural frequencies using theoreticalanalytical method. Methodology to analyze vibration influence on the welded structures is briefly summarized and recommended to be used as comparison data in further structural assessment.

\section{Introduction}

Today, vibration is considered to be one of environmental factors damaging not only structures but also the people who use them. It is necessary to avoid the fatigue failure of vehicles, vessels, and other essential structures such as the failure of normal structures to protect themselves from motion. Exact Vibration Analysis is very important when designing structures. Meanwhile the drying and assembly of general structures not only in the field of building civil and aviation but throughout the industry is dependent on welding. In particular, rivet method was mainly used in the assembly process of shipbuilding and sea areas, but recently the development of the welding process and the construction of ships and offshore structures by the most complex and large construction method were used to create the most common. Welding is so widely used for the whole industry, and it is predicted that welding will alter the natural frequencies of a structure since it changes its stiffness, it is difficult to find a study on the effects of welding on the natural frequencies of a structure. Shin conducted a study on the Timoshenko Beam theory through his analysis using the Finite Element Method for Free Vibration of Simply supported beam and Cantilever Beams [1]. Shin \& Yun \& Park proposed a design that is highly resistant to weld deformation in order to minimize deformation of the deck plate welds during manufacture [2]. 
In this study, the plates are welded using butt welding, which is the most popular method in the shipyard, measured the natural frequencies. And compare it with the numerical analysis results to determine the qualitative trends of welding on the natural frequencies of the plate.

\section{Specimens and Experiments}

\subsection{Specimens}

The specimens used in the experiments with this study were a $3 \mathrm{~mm}$ thick plate and were actually produced using the GTAW technique which is commonly used in shallow welding in shipyard.

The shape of the specimen is made of a square with a $300 \mathrm{~mm}$, and a rectangular with a length $300 \mathrm{~mm}$ by width $200 \mathrm{~mm}$, a length $200 \mathrm{~mm}$ by width $300 \mathrm{~mm}$ and all specimens are of constant thickness. The weld parallel to the boundary condition is horizontal weld. Vertical one is vertical weld. There are six main types of square specimens. Unwelded, once, twice horizontal weld and once, twice vertical weld, and one cross weld. And there are four main types of rectangular specimens depending on the boundary conditions of the weld. Unwelded, single horizontal weld, single vertical weld, cross weld. At this time, the mount was $60 \mathrm{~mm}$ wide, $60 \mathrm{~mm}$ wide, and $400 \mathrm{~mm}$ long (Figure 1, Figure 2).

To avoid interference with the natural frequency of the mount and plate, the value of the primary natural frequency of the mount was calculated theoretically, and it was confirmed that the value is measured in the range of higher than 7th natural frequencies of the plate. Although the size of the steel plates is not entirely consistent due to acceptable tolerances in the welding process and the steel plate foundation process, this is also considered in shipyard. In this study, the aim is to identify qualitative trends, so the experiments were carried out, taking into consideration the previous errors.

Table 1 shows the specifications of steel plates used for experiments. Square plates fixed the length of $300 \mathrm{~mm}$ on the mount. Rectangular plate1 fixed the length of $300 \mathrm{~mm}$ on the mount, rectangular plate 2 fixed the length of $200 \mathrm{~mm}$ on the mount. Table 2 shows the welding conditions used in the preparation of specimens. The specimens used in the experiments were commissioned by the experts who were welding in the shipyard.

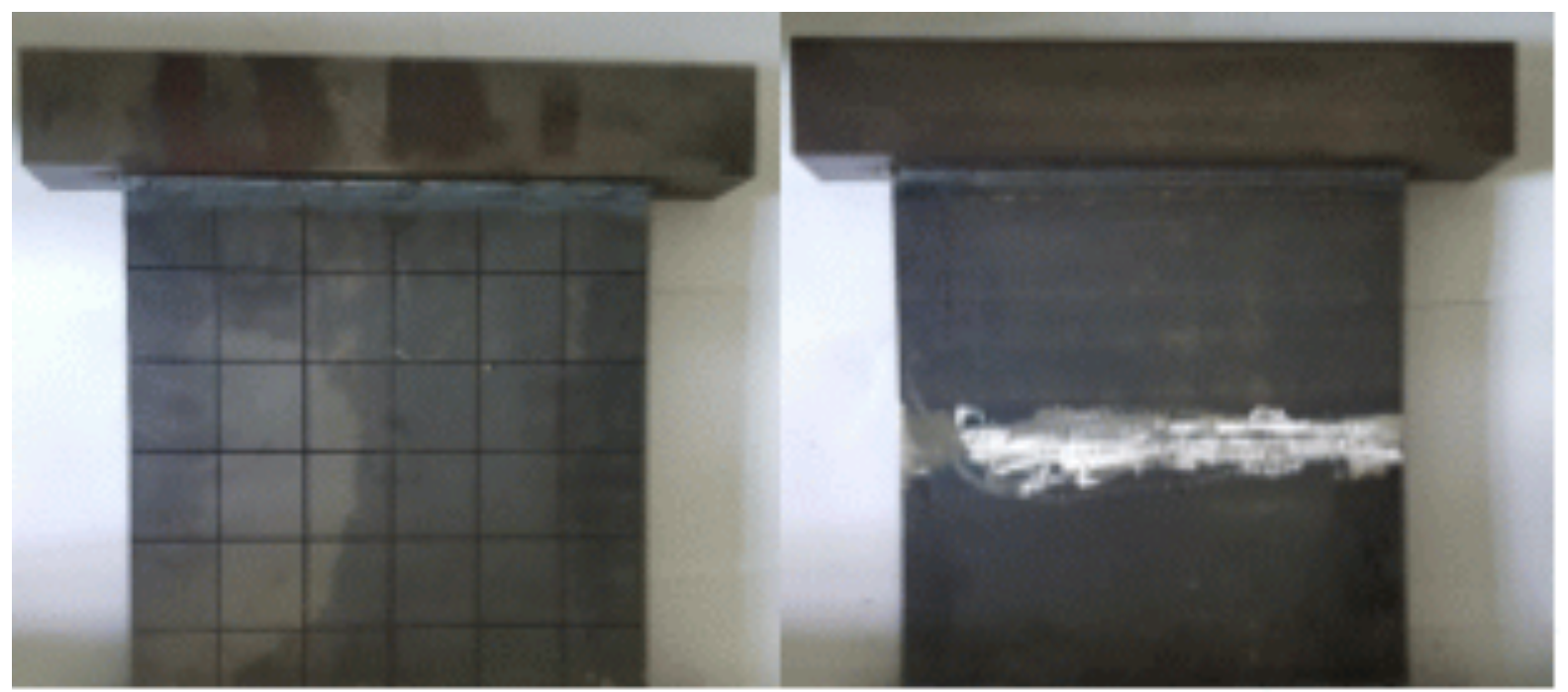

Figure 1: Experiment Specimen 


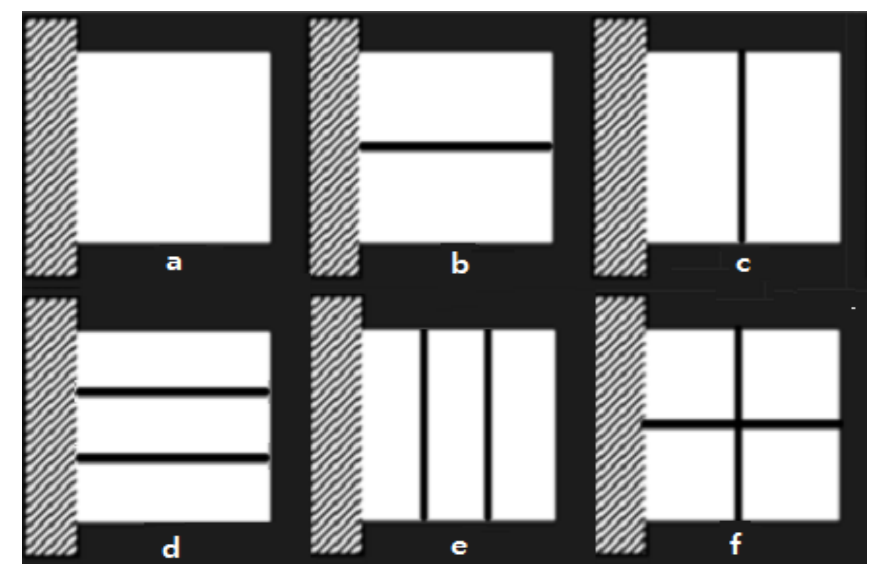

Figure 2: Welding point of steel plate

a: Original Plate, b: Once vertical weld, c: Once horizontal weld, d: twice vertical weld, e: twice horizontal weld, f: cross weld.

Table 1: Specification of Steel Plate

\begin{tabular}{|l|c|c|c|}
\hline & Square plate & Rectangular Plate 1 & Rectangular Plate 2 \\
\hline Length $[\mathbf{m m}]$ & 300 & 300 & 200 \\
\hline Breadth $[\mathbf{m m}]$ & 300 & 200 & 300 \\
\hline Thickness $[\mathbf{m m}]$ & 3 & 3 & 3 \\
\hline Young's Modulus[GPa] & 210 & 210 & 210 \\
\hline Mass Density $\left[\mathbf{k g} / \mathbf{m}^{3}\right]$ & $7.86^{*} 10^{3}$ & $7.86^{*} 10^{3}$ & $7.86^{*} 10^{3}$ \\
\hline Poisson's Ratio & 0.26 & 0.26 & 0.26 \\
\hline
\end{tabular}

\subsection{Experiment}

The measuring device consists of an FFT analyser (b\&k, 3560-B-040), an impact hammer (b\&k, 8206-001), an accelerometer (ENDEVCO, 751-100) and a computer, as shown in Figure 3. Measurement plates were divided into 25 measuring points, each measuring board five horizontal and five vertical sides, and an Impact test was conducted on average of five times. To obtain mode characteristics using the measured signals from the FFT analyzer, we used the signal analysis program PULSE Labshop ( $\mathrm{b} \& \mathrm{k}$ ) and MATLAB is used to represent a natural mode from measured characteristics.

Table 2: Welding Conditions

\begin{tabular}{|c|c|c|c|}
\hline Process & Electrode & Current Intensity & Shield Gas \\
\hline TIG & AWS A5.18 & $100 \sim 120$ & $\mathrm{Ar}$ \\
\hline GTAW $)$ & ER70S-6 & 120 & \\
\hline
\end{tabular}

To ensure that the natural frequency of the plate containing the weld was measured correctly, a natural frequencies measurement was carried out on the plate without the weld. 


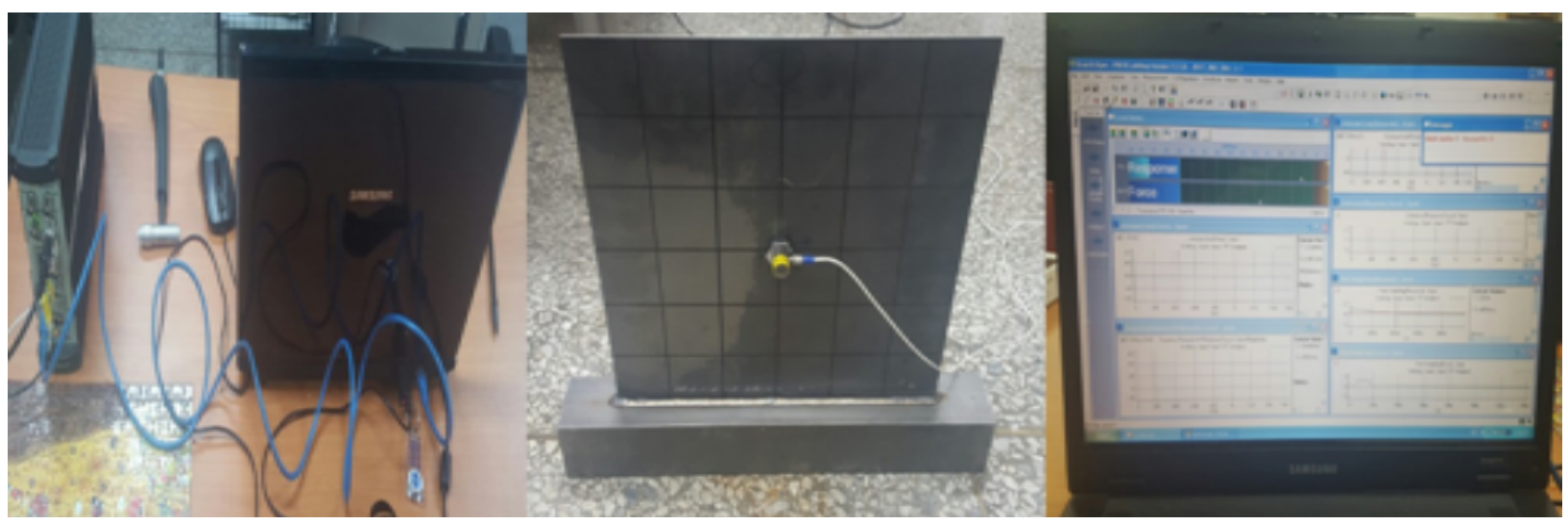

Figure 3: Experimental apparatus for modal analysis

\section{Result and Discussions}

\subsection{Square Plate}

The natural frequencies obtained in the experiment with a square plate were shown in Table 3 and the unique modes in Figure 4. As shown in Table 3, in natural modes higher than the fourth degree, the natural frequencies of the welded plates are generally higher than those of the original. And the natural frequencies appear high in order of horizontal, vertical and cross welding. However, the primary and secondary natural modes showed that the natural frequencies of weld once horizontally and of weld twice vertically were lower than those of the original. Once-vertically weld appears to have higher natural frequency in primary natural mode, twice horizontal weld lower than original in primary natural mode, and, in secondary natural mode, higher than original. In cross-welding, it is also shown to be higher than the original in the primary natural mode and lower in the secondary unique mode. This is likely because of the change in stiffness due to welding and the mode shape of the natural frequency. As shown in Figure 4, the direction of weld, the mode shape, and the boundary part combine to suppress the vibration mode and tend to increase the natural frequency. If they are in the direction of further weighting of the mode displacement, it is judged that the increase in inertia forces reduces the natural frequency. Therefore, once vertical weld tends to increase its natural frequency with increased stiffness, and once horizontal weld tends to decrease its natural frequency with increased inertia.

In addition, when the weld is close to a boundary condition, interaction tends to inhibit the mode and increase the natural frequency. As shown in Figure 4 If the primary mode is farther from the boundary the displacement is greater, the horizontal weld will not move as much in relation to the mode displacement. Vertical welds inhibit mode displacement by increasing stiffness over the origin. Cross weld shows natural frequency between single vertical weld and one horizontal weld, as its natural frequency is low due to horizontal weld and its natural frequency is high due to vertical weld. In addition, in twice horizontal welds, the part of the weld that is farther than the horizontal once shows a tendency to reduce its natural frequency, and the part that is close to the boundary condition tends to increase its natural frequency. Therefore, the natural frequency is higher than that of once horizontal weld. This is believed to be due to the higher stiffness increase due to the influence of the boundary condition, rather than to an increase of inertial force. 
Table 3: Natural Frequencies of Square Plate

\begin{tabular}{|c|c|c|c|c|c|c|}
\hline & $\begin{array}{c}\text { Original } \\
{[\mathbf{H z}]}\end{array}$ & $\begin{array}{c}\text { Once } \\
\text { Horizontal } \\
{[\mathbf{H z}]}\end{array}$ & $\begin{array}{c}\text { Once } \\
\text { Vertical } \\
{[\mathbf{H z}]}\end{array}$ & $\begin{array}{c}\text { Twice } \\
\text { Horizontal } \\
{[\mathbf{H z}]}\end{array}$ & $\begin{array}{c}\text { Twice } \\
\text { Vertical } \\
{[\mathbf{H z}]}\end{array}$ & $\begin{array}{c}\text { Cross } \\
{[\mathbf{H z}]}\end{array}$ \\
\hline $\mathbf{1}^{\text {st }}$ & 26 & 19 & 36 & 24 & 27 & 33 \\
\hline $\mathbf{2}^{\text {nd }}$ & 53 & 49 & - & 67 & 48 & 50 \\
\hline $\mathbf{3}^{\text {rd }}$ & 155 & 162 & - & 164 & 136 & - \\
\hline $\mathbf{4}^{\text {th }}$ & 208 & - & - & 236 & 220 & 217 \\
\hline $\mathbf{5}^{\text {th }}$ & 400 & 428 & 455 & 399 & 391 & - \\
\hline
\end{tabular}

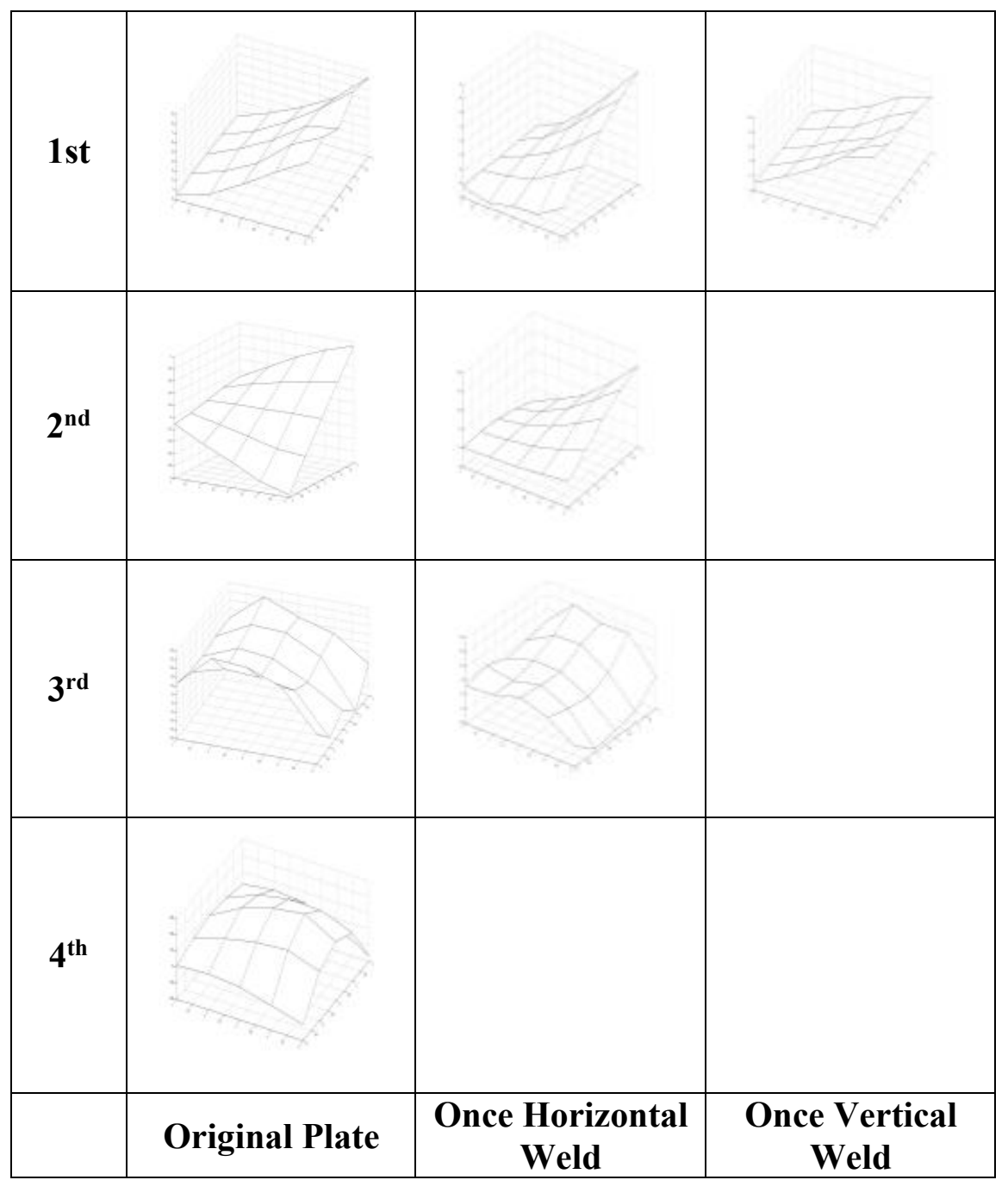

(a) 


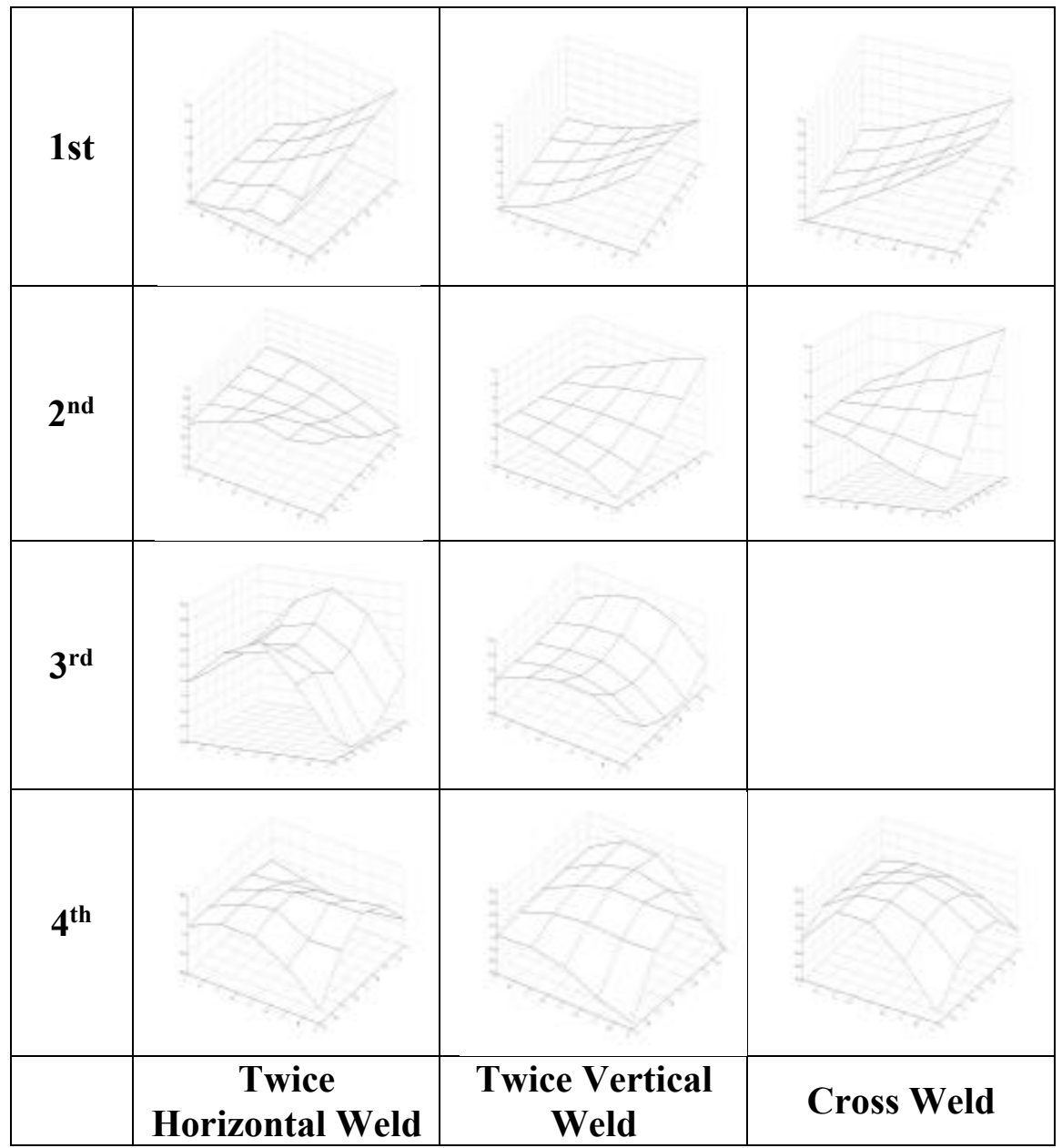

(b)

Figure 4: Experimental mode Shapes of square plate

\subsection{Rectangular Plate}

For rectangular plates, parts of the $300 \mathrm{~mm}$ weld boundary condition and the $200 \mathrm{~mm}$ weld boundary condition were considered, respectively.

\subsubsection{0 mm boundary condition}

The results of the experiment with the $300 \mathrm{~mm}$ boundary condition plate are shown in the following Tables 4 and Figure 5.

Table 4: Natural Frequencies of Rectangular Plate

\begin{tabular}{|c|c|c|c|c|}
\hline & $\begin{array}{c}\text { Original } \\
{[\mathbf{H z}]}\end{array}$ & $\begin{array}{c}\text { Once Horizontal } \\
{[\mathbf{H z}]}\end{array}$ & $\begin{array}{c}\text { Once Vertical } \\
{[\mathbf{H z}]}\end{array}$ & $\begin{array}{c}\text { Cross } \\
{[\mathbf{H z}]}\end{array}$ \\
\hline $\mathbf{1}^{\text {st }}$ & 56 & 48 & 58 & 57 \\
\hline $\mathbf{2}^{\text {nd }}$ & - & - & - & - \\
\hline $\mathbf{3}^{\text {rd }}$ & 228 & 168 & 233 & - \\
\hline $\mathbf{4}^{\text {th }}$ & 392 & & & - \\
\hline $\mathbf{5}^{\text {th }}$ & - & - & - & - \\
\hline $\mathbf{6}^{\text {th }}$ & 550 & 551 & 566 & 752 \\
\hline
\end{tabular}




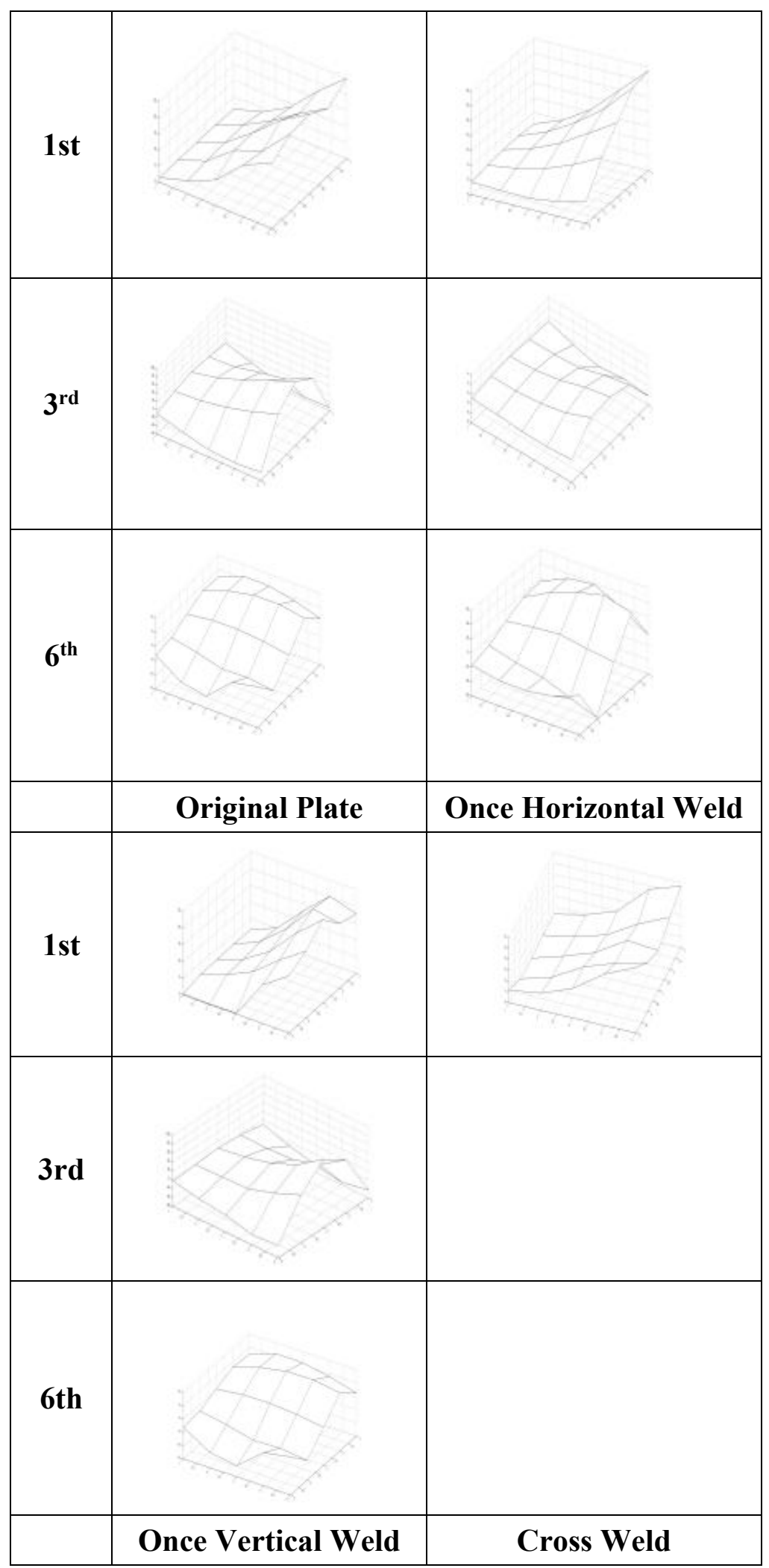

(b)

Figure 5: Experimental Mode Shapes of Rectangular Plate 
As shown in Table 4, once horizontal weld appears to have a low natural frequency, while once vertical weld has a high natural frequency. Cross-weld involves a natural frequency between one vertical and one horizontal natural frequency in the first mode.

As compared to squares, natural frequencies tend to be relatively high, as welds are closer to the boundary. However, in the case of rectangles, it is the lateral half wave mode in the second and third modes, and as shown in the mode features, the weld moves exactly as the mode does, resulting in increased inertia forces. This has the effect of lowering natural frequencies. In the fourth mode it was considered unlikely that the weld would have any influence on the natural frequency since the horizontal primary mode would be the main mode. However, the mode appears to influence closely because the farther away it is from the boundary, the smaller the downward and upward displacement is occurring.

\subsubsection{0 mm boundary condition}

The results of the experiment with the $300 \mathrm{~mm}$ boundary condition plate are shown in the following Tables 5 and Figure 6.

Table 5: Natural Frequencies of Rectangular Plate

\begin{tabular}{|c|c|c|c|c|}
\hline & $\begin{array}{c}\text { Original } \\
{[\mathbf{H z}]}\end{array}$ & $\begin{array}{c}\text { Once Horizontal } \\
{[\mathbf{H z}]}\end{array}$ & $\begin{array}{c}\text { Once Vertical } \\
{[\mathbf{H z}]}\end{array}$ & $\begin{array}{c}\text { Cross } \\
{[\mathbf{H z}]}\end{array}$ \\
\hline $\mathbf{1}^{\text {st }}$ & 26 & 27 & 23 & 24 \\
\hline $\mathbf{2}^{\text {nd }}$ & 81 & 72 & 62 & 56 \\
\hline $\mathbf{3}^{\text {rd }}$ & 171 & 161 & 128 & 173 \\
\hline $\mathbf{4}^{\text {th }}$ & 301 & 297 & 243 & 246 \\
\hline $\mathbf{5}^{\text {th }}$ & 432 & 418 & - & 464 \\
\hline
\end{tabular}

\begin{tabular}{|c|l|l|}
\hline $\mathbf{1 s t}$ & \multicolumn{1}{|c|}{} \\
\hline & & \\
\hline $\mathbf{2}^{\text {nd }}$ & & \\
\hline & & \\
\hline $\mathbf{3}^{\text {rd }}$ & & \\
& & \\
\hline
\end{tabular}




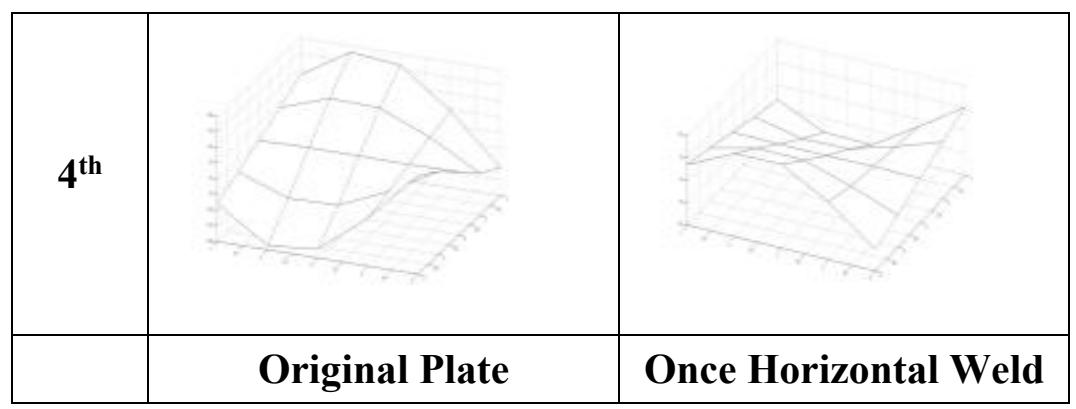

(a)

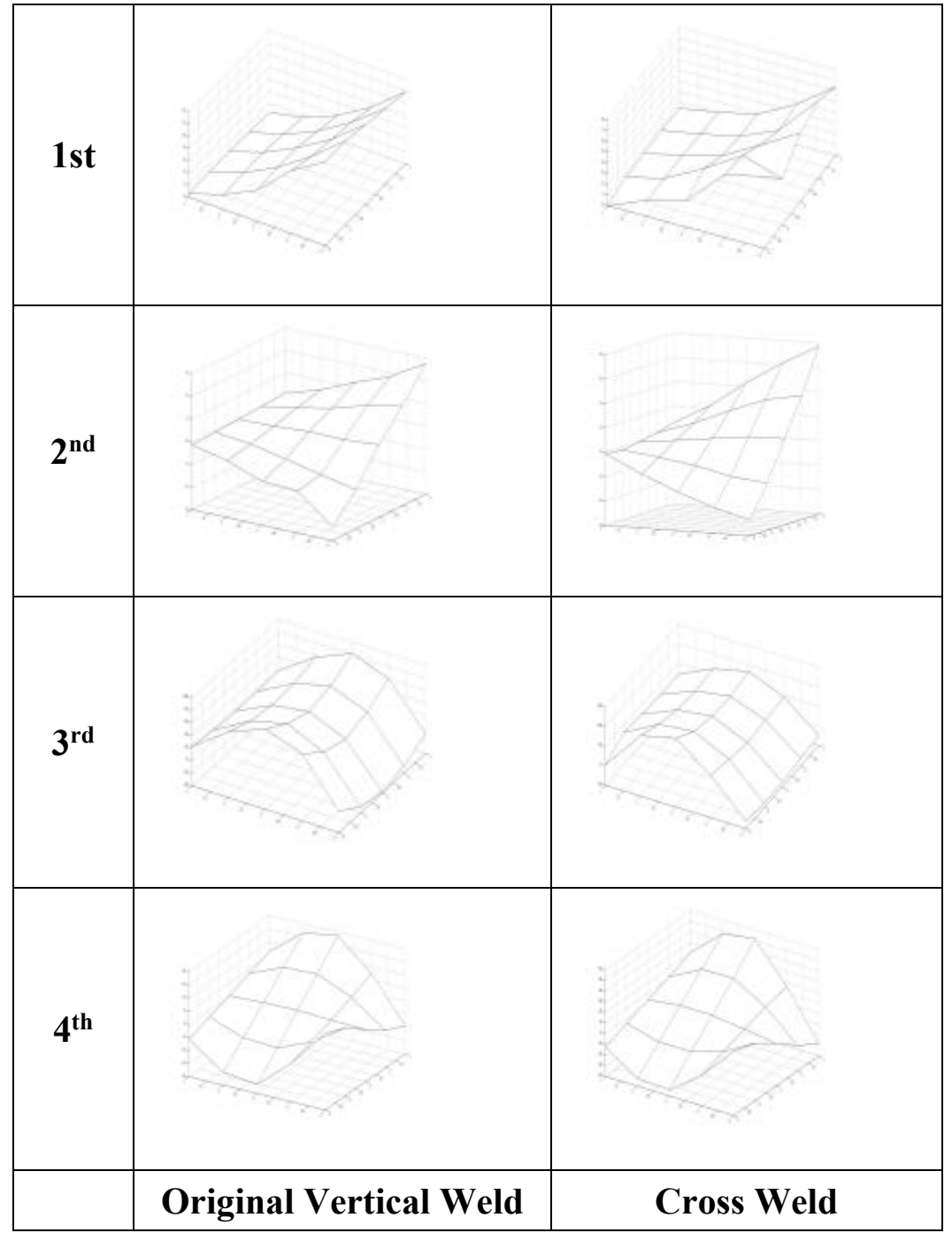

(b)

Figure 6: Experimental Mode Shapes of Rectangular Plate (Fixed : 200mm)

In both horizontal and vertical welds, the natural frequencies are generally lower than original one. Cross-weld shows low in primary and secondary modes, high in tertiary modes, and low again in fourth modes. When compared to the square and the rectangular $300 \mathrm{~mm}$ boundary conditions, it can be seen that the tendency of natural frequencies is different. That is, it can be seen that for single vertical welding, the natural frequency is lower than for single horizontal weld. This is seen as the effect of relatively few boundary conditions. 


\subsection{Original Plates}

Figure 7 represented the natural frequencies of the pates in each specimen shape. Here $300 \mathrm{~mm} 300$ $\mathrm{mm}$ and $300 \mathrm{~mm} 200 \mathrm{~mm}$ were welded in the $300 \mathrm{~mm}$ section. $200 \mathrm{~mm} 300 \mathrm{~mm}$ was welded to the $200 \mathrm{~mm}$ section. As shown in the figure, the larger the part of the boundary condition relative to the area, the higher the natural frequency is to be seen, and the mode shape determines the variation in the natural frequency.

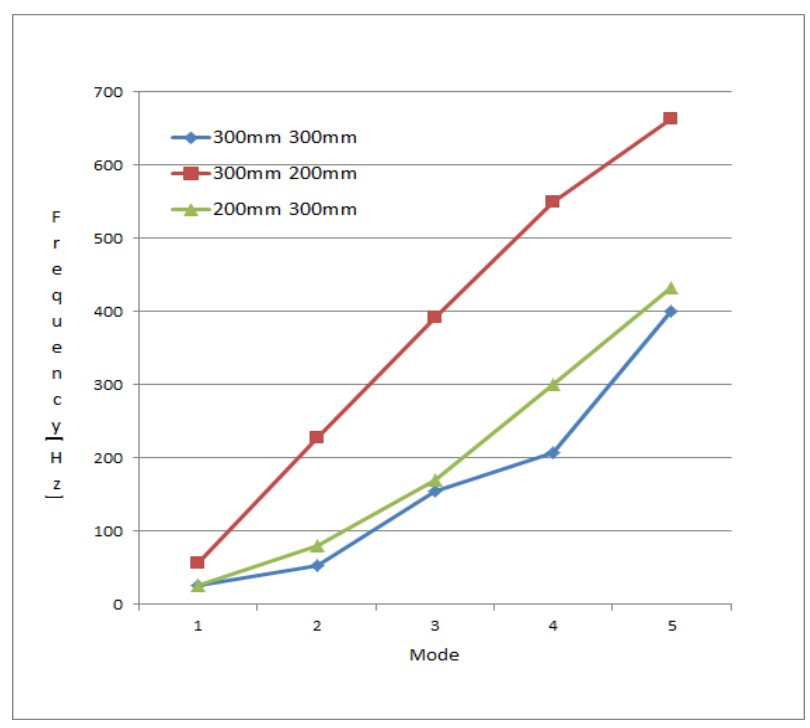

Figure 7: Natural Frequencies of non-weld plates.

\section{Conclusion}

The results of performing an experimental mode analysis on the plates containing different types of welds, as shown above, show the following.

When looking at the length of the portion secured on the mount as a boundary condition, it was possible to see that the natural frequency varied depending on the boundary condition and the area of the plate.

In the case of welded plates in the horizontal direction, it was found that the primary and secondary natural frequencies were low, regardless of the boundary conditions. Cross welding also shows a value between the horizontal and vertical welding. Have a value closer to the result of welding in the vertical direction than if welded in the horizontal direction, independent of the boundary conditions.

Square plate welded twice in the longitudinal direction, it is likely that the natural frequency of the first to third series is lower, and in the case of specimens whose boundary conditions are fixed to $200 \mathrm{~mm}$, it is likely that they are made in the vertical direction. Where the boundary conditions are fixed to a $200 \mathrm{~mm}$ area, more detailed consideration is needed for this part because, when welded in a vertical direction, it tends to decrease the natural frequency rather than the tendency of other specimens.

In this study, trends were analyzed through comparison of experimental results. The results of the experiment will then be applied to a theoretical analysis using the Finite Element Act to review the boundary conditions and to analyze the various types of structures. This study will be a criterion for the vibration analysis of the welded structures. 


\section{References}

[1] Shin, Young-Shik, "Free Vibration Analysis of a Timoshenko Beam Finite Element”, Report, Vol.11 No.1, 1983.

[2] Shin, S.B., Yoon, J.K. and Park, D.H. "A Study on the Angular Distortion at the Stiffened Panel Structure", The Korean Welding and Joining Society, Summary book of Special Lecture and Conference, Vol. 2 pp.318 320, 1999.

[3] American Welding Society, AWS D1.1 Structural Welding Code - Steel.,2015.

[4] Bae, K.Y. and Choi, T.W. "An Analysis of Thermal Stress and Angular Distortion in Bead-on-Plate Welding Incorporating Constrained Boundary Conditions.”, The Korean Welding and Joining Society, Vol. 17, No. 3. 1999.

[5] Choi, W.D. "(A) study on the thermal stress analysis and residual stress measurement of thin plate during TIG welding”, Chungnam National University, 2002.

[6] Kim, K.C., Han, S.Y. and Jung, J.H. Natural Vibrations of Rectangular Stiffened Plates with Inner Cutouts, Journal of the Society of Naval Architects of Korea, Vol. 24, No.3, 1987.

[7] Lee. J.M. and Kim, K.C. "Vibration Analysis of Rectangular Thick Plates Using Mindlin Plate Characteristic Functions", Transactions of the Society of Naval Architects of Korea, Vol. 33, No. 2, 1996 